\title{
Surface Tension of Liquid Ti-Al Alloys
}

\section{Liu Xuyang, Lv Xuewei, Li Chunxin, Chen Jie, Bai Chenguang}

Chongqing University, Chongqing 400044, China

\begin{abstract}
The surface tension of liquid Ti-Al alloys at $1758 \mathrm{~K}$ was determined by an improved sessile drop method. The surface tension of liquid Ti-Al alloys was calculated using the Butler's model and several modified ideal solution models. Results show that the surface tension of liquid Ti-Al alloy decreases with increased Al concentration. Experimental results agree well with both the Butler's model and the modified ideal solution model. The segregation of Al atoms to the surface occurs at all bulk concentrations of $\mathrm{Ti}-\mathrm{Al}$ alloys. Al with lower surface tension prefers to segregate on the surface of liquid Ti-Al alloy, whereas Ti with higher surface tension prefers to segregate inside the molten alloy. The effect of surface active solute on the surface tension of liquid Ti-Al alloy was also discussed. Sulfur is found to have a larger effect on the surface tension of alloy. The surface tension of liquid Ti-Al alloy decreases with increased sulfur concentration. Sulfur concentration on the surface is higher than that in the bulk. Thus, the adsorption of sulfur for Ti-Al alloys is a positive adsorption.
\end{abstract}

Key words: Ti-Al alloys; thermodynamic properties; surface tension

Ti-Al alloy, as a typical high temperature alloy, has become a highly promising material in aircraft engine parts with low density, high elasticity modulus, and high specific strength ${ }^{[1]}$. The refining, casting, welding and coating process for manufacturing these parts with high mechanical performance is influenced by the physicochemical properties of molten alloys.

Surface tension is a fundamental parameter of the surface state of melt, which is closely related to crystallization and wettability of a casting mold. These factors affect the formation process of casting and directly determine the quality of castings. Thus, surface properties of metal or alloy have been the subject of many investigations ${ }^{[2-6]}$. Adachi ${ }^{[7]}$ studied the surface tension of Si-Cu binary alloys and compared their surface properties. Schmitz ${ }^{[8]}$ measured the surface tension of liquid Al-Cu binary alloy from $1100 \mathrm{~K}$ to $1900 \mathrm{~K}$. Cordovilla ${ }^{[9]}$ measured the density and surface tension of $\mathrm{Mg}$-Al alloy using the maximum bubble pressure system.

Although the surface properties of alloys are widely reported, few studies have been conducted to study the surface tension of Ti-Al alloy at high temperature due to its high melting point. Surface tension measurement by experiments is more focused on Ti-Al alloys with 0 at $\%$ to 50 at $\% \mathrm{Al}$. Ricci ${ }^{[6]}$ calculated the surface tension of Ti-Al alloy within the entire range of composition at $1973 \mathrm{~K}$ based on Butler's equation. Wei ${ }^{[10-12]}$ measured the surface tension of $\mathrm{Ti}_{80} \mathrm{Al}_{20}{ }^{[10]}$, $\mathrm{Ti}_{55} \mathrm{Al}_{45}{ }^{[11]}$ and $\mathrm{Ti}_{49} \mathrm{Al}_{51}{ }^{[12]}$ alloy over a broad temperature range by an oscillating drop method, which shows that surface tension linearly varies with temperature.

In addition, wettability between metal and ceramic significantly affects the preparation of metal-ceramic composites $^{[13]}$. Adding alloying elements to the matrix is an effective approach to improve the wettability. The principle is based on decreasing the surface tension of liquid alloy and decreasing solid-liquid interfacial energy at the particle-matrix interface by adding alloying elements ${ }^{[14]}$. In general, sulfur, oxygen, selenium, and tellurium are strongly surface active elements, which significantly influence the surface tension of metallic solutions despite their low solubility ${ }^{[15]}$.

Due to the insufficient knowledge on the thermophysical properties of the Ti-Al binary system and the importance of the preparation process of composite materials, in the present work, the surface tension of Ti-Al alloys was studied by a sessile drop method and several calculation models. The

Received date: December 23, 2015

Foundation item: National Key Basic Research Development Program of China (“973” Program) (2013CB632603)

Corresponding author: Lv Xuewei, Ph. D., Associate Professor, College of Materials Science and Engineering, Chongqing University, Chongqing 400044, P. R. China, Tel: 0086-23-65112631, E-mail: lvxuewei@163.com 
effects of the surface active element sulfur on the surface tension of Ti-Al alloy were also analyzed.

\section{Experiment}

$\mathrm{Al}_{2} \mathrm{O}_{3}$ substrates (99\% purity) were used to achieve non-wetting drop shape because of their non-wettability with the alloy. Substrate surfaces were polished with diamond pastes $(3.5,2.5,1.5,1.0$, and $0.5 \mu \mathrm{m})$, and cleaned with acetone three times to remove impurities using a Q2200E ultrasonic cleaner before each experiment. Roughness of the substance surface yielded after polishing was detected with an IFM microscope (Boyue Instruments Co., Ltd., Dektak 150), and the average roughness $\left(R_{\mathrm{a}}\right)$ was about $20 \mathrm{~nm}$ to $25 \mathrm{~nm}$.

Five alloys with different $\mathrm{Al}$ contents (54 at\%, 64 at\%, 72 at $\%, 81$ at $\%$, and 88 at $\%$ ) were used in the present study. Pure $\mathrm{Ti}(99.82 \%)$ and pure $\mathrm{Al}(99.95 \%)$ were used to prepare Ti-Al alloy by a powder metallurgy method. To obtain a more uniform composition, $\mathrm{Ti}$ and $\mathrm{Al}$ powders were mixed for 10 min in argon atmosphere by high-energy ball milling (PM100, RETSCH, Germany) at a rotation speed of $200 \mathrm{r} / \mathrm{min}$. The mixture was then uniaxially pressed in a hydraulic presser at $20 \mathrm{MPa}$. The pieces were sintered at $1373 \mathrm{~K}$ with a vacuum of $\sim 0.07 \mathrm{MPa}$ for $6 \mathrm{~h}$. After sintering, the alloys were cut into cubic pieces $(\sim 0.03 \mathrm{~g})$ and cleaned in the ultrasonic cleaner.

Wetting experiments were carried out by the improved sessile drop method, showed in Fig.1. $\mathrm{Al}_{2} \mathrm{O}_{3}$ substrate was pre-placed on the alumina supporter in the center of the chamber and adjusted to a horizontal position. Ti-Al alloy was placed in a stainless-steel tube with a flexible connector on top of the dropping device outside the chamber, which connected an open alumina tube on the right side above $\mathrm{Al}_{2} \mathrm{O}_{3}$ substrate.

The chamber was first evacuated to $5 \mathrm{~Pa}$ at room temperature only with a rotary pump and further evacuated to $5 \times 10^{-4}$ Pa with a molecular pump. Ar gas (99.9999\%) purified by passing through a magnesium-containing furnace at $723 \mathrm{~K}$ was introduced to the chamber under $80 \mathrm{kPa}$ pressure to mitigate the evaporation of $\mathrm{Al}$ at high temperatures. The chamber was then heated to $1237 \mathrm{~K}$ at $20{ }^{\circ} \mathrm{C} / \mathrm{min}$ and

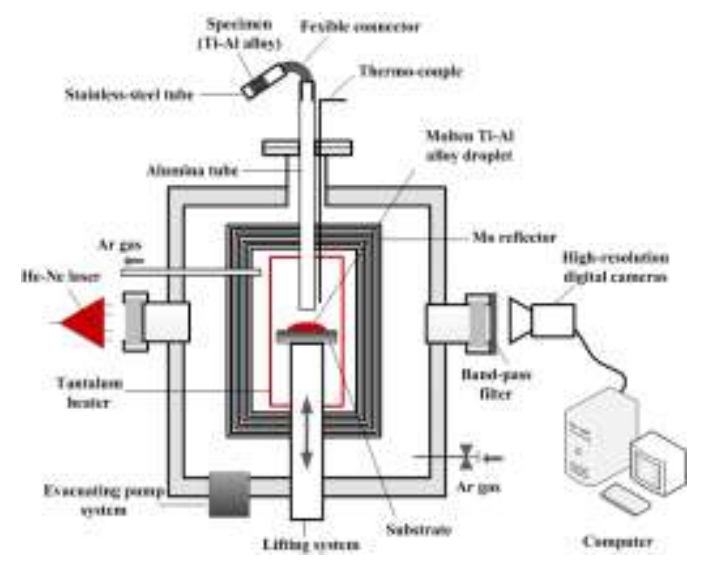

Fig.1 Schematic of high-temperature wettability measurement continuously up to $1758 \mathrm{~K}$ at $10{ }^{\circ} \mathrm{C} / \mathrm{min}$. After temperature and pressure were stabilized, Ti-Al alloys were dropped from the flexible connector through the stainless steel and alumina tubes and finally rested on $\mathrm{Al}_{2} \mathrm{O}_{3}$ substrate. As soon as the samples dropped on the substrate surface, the alloy profile was recorded using high-resolution digital cameras.

After the experiment, the samples were cooled to room temperature at $15{ }^{\circ} \mathrm{C} / \mathrm{min}$. The computer software Axisymmetric Drop Shape Analysis was used to calculate the surface tension. The principle of measuring surface tension was based on the Laplace equation.

\section{Calculation Models of Surface Tension for Ti-Al}

Butler's equation is a classical model for calculating the surface tension of binary and ternary alloys ${ }^{[16-18]}$. This model divides a solution into surface and bulk phases and is based on the assumption that the surface is in chemical equilibrium with the bulk. The surface tension of liquid alloys can be calculated as follows:

$$
\begin{aligned}
& \sigma=\sigma_{i}+\frac{R T}{S_{i}} \ln \frac{X_{i}^{\mathrm{S}}}{X_{i}^{\mathrm{B}}}+\frac{1}{S_{i}}\left[G_{i}^{\mathrm{Ex}, \mathrm{S}}\left(T, X_{i}^{\mathrm{S}}\right)-G_{i}^{\mathrm{Ex}, \mathrm{B}}\left(T, X_{i}^{\mathrm{B}}\right)\right] \\
& \sigma=\sigma_{j}+\frac{R T}{S_{j}} \ln \frac{X_{j}^{\mathrm{S}}}{X_{j}^{\mathrm{B}}}+\frac{1}{S_{j}}\left[G_{j}^{\mathrm{Ex}, \mathrm{S}}\left(T, X_{i}^{\mathrm{S}}\right)-G_{j}^{\mathrm{Ex}, \mathrm{B}}\left(T, X_{i}^{\mathrm{B}}\right)\right](2)
\end{aligned}
$$

where $R$ and $T$ are the gas constant and temperature, respectively; $\sigma, \sigma_{i}$, and $\sigma_{j}$ are the surface tension of alloy and pure components $i$ and $j$, respectively; $S_{i}$ and $S_{j}$ are the molar surface area of component; $G_{i}^{\mathrm{Ex}, \mathrm{S}}\left(T, X_{i}^{\mathrm{S}}\right)$ and $G_{i}^{\mathrm{Ex}, \mathrm{B}}\left(T, X_{i}^{\mathrm{B}}\right)$ are the partial excess free energy of $i$ in surface and bulk phases as a function of $T$ and $X_{i}$, respectively; and $X_{i}^{\mathrm{S}}$ and $X_{i}^{\mathrm{B}}$ are component contents of $i$ in surface and bulk phases, respectively.

The molar surface area of the pure component $i$ can be described by the following equation:

$$
S_{i}=1.091 N_{0}\left(\frac{M_{i}}{\rho_{i}}\right)^{2 / 3}
$$

where $N_{0}$ is Avogadro's number, and $M_{i}$ and $\rho_{i}$ are atomic mass and density, respectively. The excess Gibbs energies of component in bulk phase was obtained by

$$
\begin{aligned}
G_{i}^{\mathrm{Ex}} & =G^{\mathrm{Ex}}+\left(1-X_{i}\right) \frac{\partial G^{\mathrm{Ex}}}{\partial X_{i}} \\
G_{j}^{\mathrm{Ex}} & =\frac{G^{\mathrm{Ex}}-X_{i} G_{i}^{\mathrm{E}}}{1-X_{i}}
\end{aligned}
$$

The relationship between the partial excess free energy in surface and bulk phases is expressed by Eq. (6) based on the same concentration dependence between partial excess free energy in bulk and surface:

$$
G_{i}^{\mathrm{Ex}, \mathrm{S}}\left(T, X_{i}^{\mathrm{S}}\right)=\beta G_{i}^{\mathrm{Ex}, \mathrm{B}}\left(T, X_{i}^{\mathrm{B}}\right)
$$

$\beta$ is an empirical or semi-empirical parameter, introduced to account for the reduced coordination number of an atom on 
the surface with respect to the bulk and its exact value depends on the underlying assumptions for the structure of liquid in the bulk and surface. Speiser et al ${ }^{[19]}$ proposed that $\beta$ is equal to 0.75 , which considers that liquid alloys have a closed-packed structure. Tanaka et $\mathrm{al}^{[20]}$ reported that $\beta$ is 0.83 based on the relaxation of the surface structure.

However, based on the great difficulty to find the partial excess free energy of component in surface and bulk phase, an ideal solution model was put forward ${ }^{[21]}$. The surface concentration of each component are given by

$$
\begin{aligned}
& X_{i}^{\mathrm{S}}=\frac{X_{i}^{\mathrm{B}}}{X_{i}^{\mathrm{B}}+X_{j}^{\mathrm{B}} / \exp \left[A\left(\sigma_{j}-\sigma_{i}\right) / R T\right]} \\
& X_{j}^{\mathrm{S}}=\frac{X_{j}^{\mathrm{B}}}{X_{j}^{\mathrm{B}}+X_{i}^{\mathrm{B}} / \exp \left[A\left(\sigma_{j}-\sigma_{i}\right) / R T\right]}
\end{aligned}
$$

where $A$ is the averaged molar surface area; thus, it is given by $A=1.091 V^{2 / 3} N_{0}^{1 / 3} . V$ is the averaged molar volume. The surface tension of alloy given by the ideal solution model is:

$$
\sigma=X_{i}^{\mathrm{S}} \sigma_{i}+X_{j}^{\mathrm{S}} \sigma_{j}
$$

The ideal solution model considered that the interactions between atoms are identical. Thus, it calculates surface tension correctly only for simple systems with weak interaction, because it cannot explain the surface depletion of surface active species for system of forming intermetallic compounds.

Thus, Egry ${ }^{[22]}$ developed a modified ideal solution model in 2004. This model considered the formation of intermetallic compounds in solid state. The energy of surface segregation is required to break intermetallic compounds formed on the surface. Therefore, Eqs.(7) and (8) can be written as follows:

$$
\begin{gathered}
X_{i}^{\text {S, modified }}=\frac{X_{i}^{\mathrm{B}}}{X_{i}^{\mathrm{B}}+X_{j}^{\mathrm{B}} / \exp \left[\left(A\left(\sigma_{j}-\sigma_{i}\right)-f(n+m) X_{i}^{\mathrm{B}^{n}} X_{j}^{\mathrm{B}^{m}}\right) / R T\right]} \\
X_{j}^{\mathrm{S}, \text { modified }}=\frac{X_{j}^{\mathrm{B}}}{X_{j}^{\mathrm{B}}+X_{i}^{\mathrm{B}} / \exp \left[\left(A\left(\sigma_{j}-\sigma_{i}\right)-f(n+m) X_{i}^{\mathrm{B}^{\mathrm{B}}} X_{j}^{\mathrm{B}^{m}}\right) / R T\right]}
\end{gathered}
$$

where $f$ is the molar binding energy of the cluster; and $n$ and $m$ are the ratios of atoms in the cluster. In this case, $n=m=1$.

Recently, Adachi ${ }^{[7]}$ considered using the atomic concentration of the surface instead of the atomic concentration of bulk in terms of energy to break compound. Thus, the surface concentration of each component is expressed by

$$
\begin{aligned}
X_{i}^{\mathrm{S}, \text { modified }} & =\frac{X_{i}^{\mathrm{B}}}{X_{i}^{\mathrm{B}}+X_{j}^{\mathrm{B}} / \exp \left[\left(A\left(\sigma_{j}-\sigma_{i}\right)-f(n+m) X_{i}^{\mathrm{S}^{n}} X_{j}^{\mathrm{S}^{m}}\right) / R T\right]} \\
X_{j}^{\mathrm{S}, \text { modified }} & =\frac{X_{j}^{B}}{X_{j}^{\mathrm{B}}+X_{i}^{\mathrm{B}} / \exp \left[\left(A\left(\sigma_{j}-\sigma_{i}\right)-f(n+m) X_{i}^{\mathrm{S}^{n}} X_{j}^{\mathrm{S}^{m}}\right) / R T\right]}
\end{aligned}
$$

Compared with the ideal solution model, the modified ideal solution model considers the interatomic interactions. Thus, it is applied to accurately predict surface segregation for a system with strong interaction, especially at the concentration near intermetallic formation. However, surface tension predicted by the ideal solution model is used for all concentrations ${ }^{[22]}$.

\section{Results and Discussions}

\subsection{Surface tension of Ti-Al alloy}

The calculated results of surface tension versus $\mathrm{Al}$ concentration at $1758 \mathrm{~K}$ based on different models are plotted in Fig.2, as shown by the dashed line. For the Butler's model, the excess Gibbs energy of Ti-Al binary alloys is obtained from Ref. [23]. The surface tension of pure $\mathrm{Al}$ at $1758 \mathrm{~K}$ was $0.744 \mathrm{~N} / \mathrm{m}^{[24]}$, whereas that of pure Ti was $1.586 \mathrm{~N} / \mathrm{m}^{[25]}$. For the ideal solution model, the selection of intermetallic phases should be based on the highest binding energy with the highest liquidus temperature in the phase diagram ${ }^{[22]}$, which was TiAl in the case of the Ti-Al system. The molar binding energy of TiAl was obtained from Ref. [26].

The calculated surface tension of Ti-Al alloys at $1758 \mathrm{~K}$ based on several models seems to have the same trend. The surface tension decreases with increasing of $\mathrm{Al}$ concentration. Results calculated by the Butler's model and the modified ideal solution model are similar. However, a large difference exists for the value calculated by the ideal solution model and the Butler's model.

Fig.2 (red dashed line) presents the measured surface tension is a function of alloy composition. Experimental results well agree with both the Butler's model and the modified ideal solution model. Small differences exist between results calculated by the modified ideal solution model and the ideal solution model. This difference is due to the effect of intermetallic compound on the Ti-Al system. The ideal solution model cannot consider the interaction between surface segregation and cluster formation.

To illustrate the surface tension changes with composition, the relationship between composition in surface and bulk phases at $1758 \mathrm{~K}$ was calculated by the Butler's model, as shown in Fig.3. Results suggest that the segregation of $\mathrm{Al}$ atoms to the surface occur at all bulk concentrations of $\mathrm{Ti}-\mathrm{Al}$ alloys. Surface concentration of $\mathrm{Al}$ as a function of bulk concentration in Ti-Al alloys differs largely. With increasing $\mathrm{Al}$

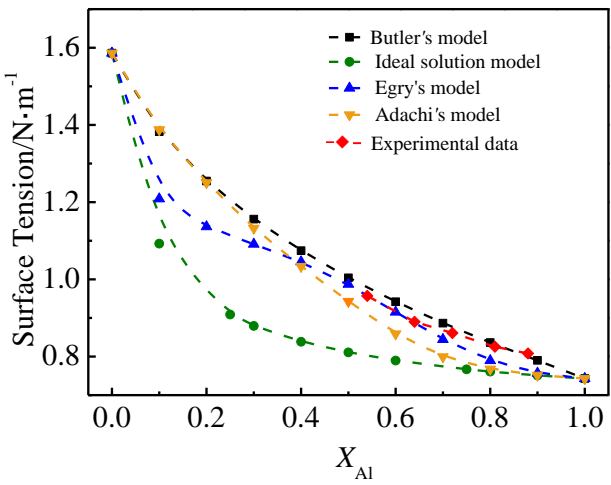

Fig.2 Calculated results of surface tension and measured experimental point versus $\mathrm{Al}$ concentration at $1758 \mathrm{~K}$ 


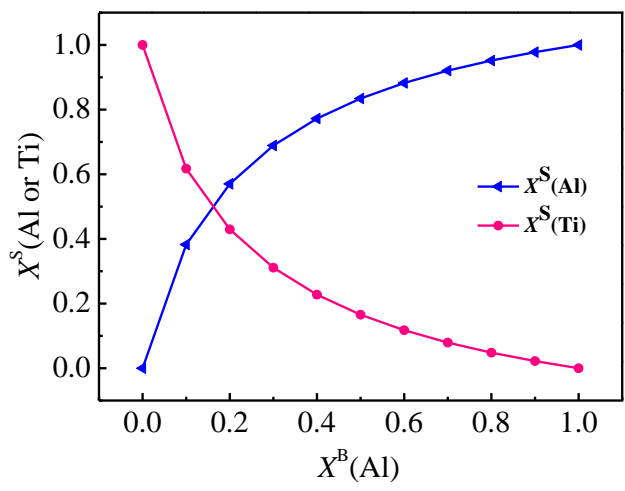

Fig.3 Relationship between composition in surface and bulk phases of $\mathrm{Al}$ and $\mathrm{Ti}$ at $1758 \mathrm{~K}$

in bulk phase, $\mathrm{Al}$ in the surface phase remarkably increases. $\mathrm{Al}$ concentration on the surface of Ti-Al alloys is higher than that in bulk phase, which indicates that $\mathrm{Al}$ in Ti-Al alloys mainly gather on the surface of Ti-Al alloys and Ti is in the bulk. This result corresponds with that of Xiao et $\mathrm{al}^{[27]}$, who considers that the element with lower surface tension tends to segregate on the surface, whereas the element with higher surface tension tends to segregate inside. Larger differences in the surface tension, atom radius, and electron configuration between solvent and solute lead to more significant segregation.

Fig.4 shows the calculated results of temperature dependence of surface tension for Ti-Al alloys based on the Butler's model. Melting temperatures were obtained from the Ti-Al binary phase diagram. The variation in surface tension with temperature is linear for Ti-Al alloys. The surface tension decreases with increasing of temperature. Table 1 summarizes the data of temperature coefficient of surface tension and surface tension at liquidus temperature of Ti-Al alloys. The temperature coefficient of surface tension of Ti-Al alloys is negative at $\mathrm{Al}$ content from 54 at $\%$ to 88 at $\%$.

Reports on the surface tension of Ti-Al alloys are limited, and the data collected are shown in Fig.5. The surface tensions measured by experiment focus more on Ti-Al alloys with 0 at $\%$ to 50 at $\% \mathrm{Al}^{[10-12]}$. The values of surface tension reported by Zhou Nowak ${ }^{[10]}$ at $1963 \mathrm{~K}$ are higher than those calculated by Nowak et $\mathrm{al}^{[6]}$ at similar temperatures. Moreover, based on experimental data, the values of surface tension reported in this work are lower than those measured by Zhou ${ }^{[10]}$.

This phenomenon is mainly due to the fact that the Ti-Al

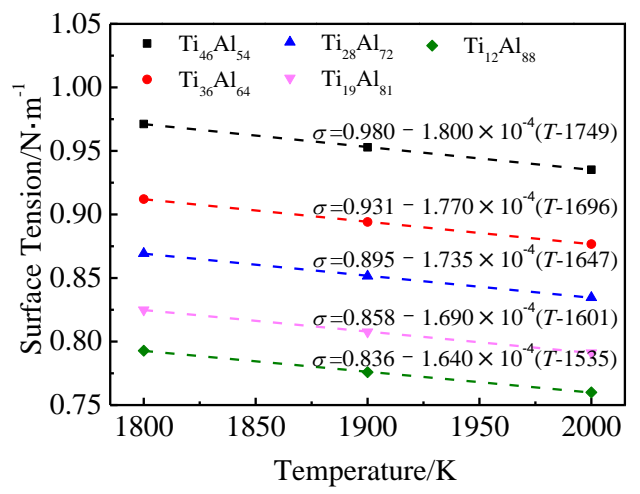

Fig.4 Calculated results of temperature dependence of surface tension of Ti-Al alloys

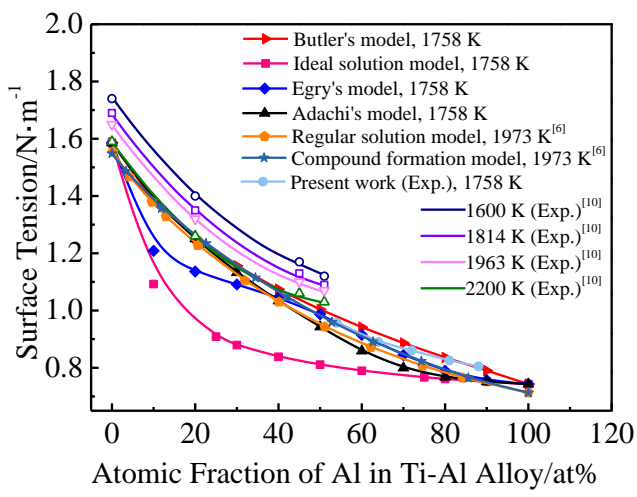

Fig.5 Surface tension of liquid Ti-Al alloy versus $\mathrm{Al}$ content reported in literature

alloy system is not ideal and polluted by surface-active elements. Oxygen, a highly surface-active element in liquid metal, can reduce surface tension and affect the reliability of experimental data even though it is only present in a very small quantity ${ }^{[28]}$. This effect reportedly depends on the oxygen level at constant temperature ${ }^{[29]}$. In the present study, the oxygen content of Ti-Al alloy samples was not accurately determined because its amount was too low. Thus, the oxygen content in liquid Ti-Al alloy was roughly estimated by its difference from the value calculated by the Butler's model. The dependence of surface tension isotherm on oxygen content was adopted from Ref. [30]. The maximum oxygen levels in Ti-Al alloy are about $6 \times 10^{-6}$. Considering the high vacuum degree of equipment, oxygen is likely to result from the raw materials. In presence of oxygen, oxygen is anticipated to occupy both $\mathrm{Ti}$ and $\mathrm{Al}$ sites.

Table 1 Temperature coefficient and surface tension at liquidus temperature for Ti-Al alloys

\begin{tabular}{|c|c|c|c|}
\hline Composition & Liquidus temperature/K & Temperature coefficient $/ \times 10^{-4} \mathrm{~N} \cdot(\mathrm{m} \cdot \mathrm{K})^{-1}$ & Surface tension at liquidus temperature $/ \mathrm{N} \cdot \mathrm{m}^{-1}$ \\
\hline $\mathrm{Ti}_{46} \mathrm{Al}_{54}$ & 1749 & -1.800 & 0.980 \\
\hline $\mathrm{Ti}_{36} \mathrm{Al}_{64}$ & 1696 & -1.770 & 0.931 \\
\hline $\mathrm{Ti}_{28} \mathrm{Al}_{72}$ & 1647 & -1.735 & 0.895 \\
\hline $\mathrm{Ti}_{19} \mathrm{Al}_{81}$ & 1601 & -1.690 & 0.858 \\
\hline $\mathrm{Ti}_{12} \mathrm{Al}_{88}$ & 1535 & -1.640 & 0.836 \\
\hline
\end{tabular}


Surface-soluble oxygen is partly removed by the selfcleaning reaction ${ }^{[31]}$, described as follows:

$4 \mathrm{Al}(\mathrm{l})+\mathrm{Al}_{2} \mathrm{O}_{3}(\mathrm{~s})=3 \mathrm{Al}_{2} \mathrm{O}(\mathrm{g})$

Therefore, surface-soluble oxygen is not as high as previously expected.

\subsection{Effect of sulfur on surface tension of Ti-Al alloy}

The effect of sulfur addition on the surface tension of Ti-88 at $\% \mathrm{Al}$ alloy at $1758 \mathrm{~K}$ is shown in Fig.6. The surface tension of Ti-88 at\% Al alloy decreases with increased sulfur addition, illustrating that sulfur has a larger effect on the surface tension of alloy. Halden ${ }^{[32]}$ also studied the effect of adding sulfur on the surface tension of liquid iron. Results show that surface tension decreases from $1.72 \mathrm{~N} / \mathrm{m}$ to $1.2 \mathrm{~N} / \mathrm{m}$ when sulfur addition is 0.1 wt $\%$. To obtain the temperature coefficient of sulfur on the surface tension of Ti-Al alloy, the surface tension of Ti-88 at\% Al alloy with 0.09 at\% sulfur addition as a function of temperature was measured (Fig.7). The surface tension decreases with the increase of temperature. This result corresponds with those of Debroy ${ }^{[33]}$. The experimental results in Fig.7 are fitted with an approximate linear relationship. Due to a small quantity of sulfur addition, the liquidus temperature of Ti-88 at\%Al-0.09 at $\% \mathrm{~S}$ is approximately equal to that of Ti- 88 at $\%$ Al. Fig.7 shows that the temperature coefficient is negative.

The segregation of the surface active component to the surface is also found to be pronounced at low temperature based on the slopes of curves in Fig.7. With increasing of

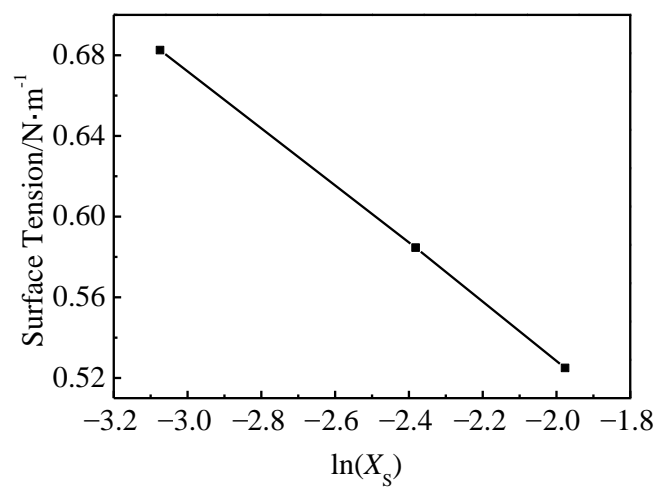

Fig.6 Effect of sulfur element on the surface tension of Ti-Al alloy

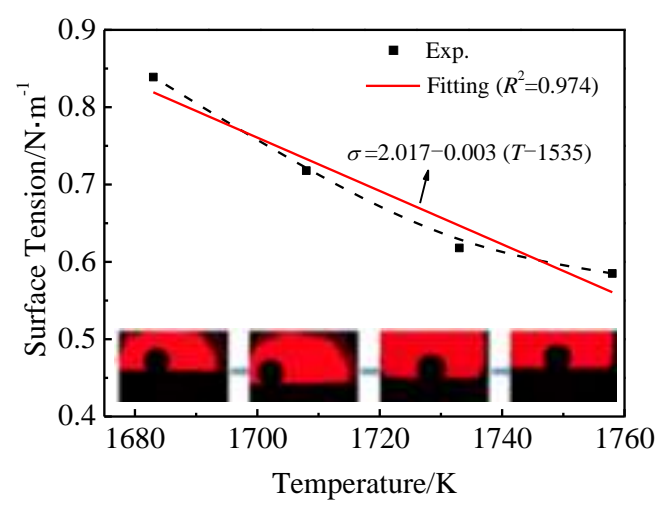

Fig.7 Surface tension of liquid Ti-88 at\% Al-0.09 at\% S alloy versus temperature

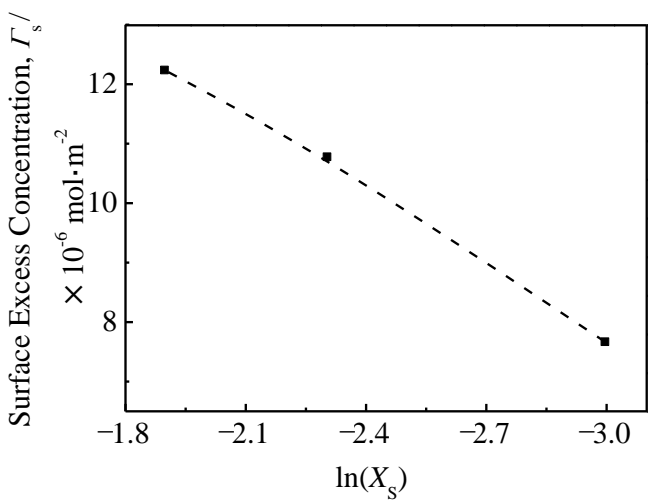

Fig.8 Excess surface concentration of additions sulfur to Ti-Al alloy at $1758 \mathrm{~K}$

temperature, the segregation ability of sulfur on the surface of Ti-Al alloy decreases.

To discuss adsorption behavior, the excess surface concentration of surface-active materials can be calculated from Gibbs' isotherm:

$$
\Gamma_{\mathrm{S}}=\frac{-\mathrm{d} \sigma}{R T \mathrm{~d} \ln a}
$$

where $\Gamma_{\mathrm{S}}$ is the surface excess at saturation, and $a$ is the activity of species in solution.

Assuming that the solution was dilute, the activity of species can be replaced by the concentration. The excess surface concentrations $\Gamma_{\mathrm{s}}$ can be determined from the slopes of curves in Fig. 6 and are plotted in Fig.8. With sulfur addition increasing, the excess surface concentration increases. Sulfur concentration on the surface is higher than that in bulk. Sulfur mainly aggregates on the surface. Thus, adsorption of sulfur for Ti-Al alloy is a positive adsorption.

\section{Conclusions}

1) The surface tension of liquid Ti-Al alloys decreases with the increasing of $\mathrm{Al}$ concentration. The experimental results agree well with both the Butler's model and the modified ideal solution model.

2) The segregation of $\mathrm{Al}$ atoms to the surface occurs at all bulk concentrations of Ti-Al alloy. Al with lower surface tension tends to segregate on the surface of liquid Ti-Al alloy, whereas $\mathrm{Ti}$ with higher surface tension tends to segregate inside of the molten alloy.

3) The surface tension of liquid Ti-Al alloy decreases with increasing of sulfur concentration. Sulfur concentration on the surface is higher than that in the bulk. The sulfur adsorption for Ti-Al alloys is the positive adsorption.

\section{References}

1 Zope R, Mishin Y. Physical Review B[J], 2003, 68(2): 24102

2 Tanaka T, Hack K, Iida $\mathrm{T}$ et al. Zeitschrift für Metallkunde[J], 1996, 87(5): 380 
3 Keene B J. International Materials Reviews[J], 1988, 33(1): 1

4 Egry I, Ricci E, Novakovic R et al. Advances in Colloid and Interface Science[J], 2010, 159(2): 198

5 Fima P. Applied Surface Science [J], 2011, 257(8): 3265

6 Nowak R, Lanata T, Sobczak N et al. Journal of Materials Science [J], 2010, 45(8): 1993

7 Adachi M, Schick M, Brillo J et al. Journal of Materials Science [J], 2010, 45(8): 2002

8 Schmitz J, Brillo J, Egry I et al. International Journal of Materials Research[J], 2009, 100(11): 1529

9 Garcia-Cordovilla C, Louis E, Pamies A. Journal of Materials Science [J], 1986, 21(8): 2787

10 Zhou K,Wang H, Wei B. Chemical Physics Letters[J], 2012, 521(9): 52

11 Zhou K, Wang H, Chang J. Applied Physics A[J], 2011, 105(1): 211

12 Zhou K, Wang H, Chang J et al. Philosophical Magazine Letters[J], 2010, 90(6): 455

13 Zhang D, Shen $\mathrm{P}$, Shi L et al. Materials Chemistry and Physics[J], 2011, 130(1): 665

14 Hashim J, Looney L, Hashmi M. Journal of Materials Processing Technology[J], 2001, 119(1): 324

15 Lupis C H. Chemical thermodynamics of Materials[M]. New York: North-Holland Publications, 1983

16 Butler J. Proceedings of the Royal Society of London. Series A [J], 1932, 135(827): 348

17 Moser Z, Gasior W, Pstruś J. Journal of Phase Equilibria[J], 2001, 22(3): 254

18 Gąsior W, Moser Z, Pstruś J. Journal of Phase Equilibria[J], 2001, 22(1): 20
19 Speiser R, Poirier D, Yeum K. Scripta Metallurgica[J], 1987, 21(5): 687

20 Tanaka T, Hara S, Ogawa M et al. Zeitschrift für Metallkunde[J], 1998, 89(5): 368

21 March N H. Atomic Dynamics in Liquids[M]. New York: Dover Publications, 1991

22 Egry I. Journal of Materials Science[J], 2004, 39(20): 6365

23 Johnson D, Chihara K, Inui H et al. Acta Materialia[J], 1998, 46(18): 6529

24 Laty P, Joud J, Desré P et al. Surface Science[J], 1977, 69(2): 508

25 Paradis P, Ishikawa T, Yoda S. International Journal of Thermophysics[J], 2002, 23(3): 825

26 Asta M. De Fontaine D, Van Schilfgaarde M et al. Physical Review B[J], 1992, 46(9): 5055

27 Xiao F, Liu L, Yang R et al. Transactions of Nonferrous Metals Society of China[J], 2008, 18(5): 1184

28 Egry I, Ricci E, Novakovic R et al. Advances in Colloid and Interface Science [J], 2010, 159(2): 198

29 Sharan A, Cramb A W. Metallurgical and Materials Transactions B[J], 1997, 28(3): 465

30 Ricci E, Passerone A, Joud J. Surface Science[J], 1988, 206(3): 533

31 Laurent V, Chatain D, Chatillon C et al. Acta Metallurgica[J], 1988, 36(7): 1797

32 Halden F, Kingery W. The Journal of Physical Chemistry[J], 1955, 59(6): 557

33 Sahoo P, DebRoy T, McNallan M. Metallurgical Transactions $B[J], 1988,19(3): 483$

\title{
Ti-Al 二元系合金的表面张力
}

\author{
刘许旸, 吕学伟, 李春新, 陈 杰, 白晨光 \\ (重庆大学, 重庆 400044)
}

\begin{abstract}
摘 要: 采用滴落法测定了在 $1758 \mathrm{~K}$ 条件下 $\mathrm{Ti}-\mathrm{Al}$ 合金的表面张力。同时采用 Butler 模型和几种改进的理想溶液模型理论计算了 $\mathrm{Ti}-\mathrm{Al}$ 合金的表面张力。结果表明, $\mathrm{Ti}-\mathrm{Al}$ 合金的表面张力随着 $\mathrm{Al}$ 含量的增加而减小。实验结果和采用 Butler 模型以及改进的理想溶液模型理 论计算的结果相一致。 $\mathrm{Al}$ 原子主要分布在熔体的表面, 而 $\mathrm{Ti}$ 由于具有高的表面张力主要分布在熔体的内部。同时也讨论了表面活性元 素硫对 Ti-Al 合金表面张力的影响。结果表明硫对合金表面张力影响很大，随着硫的增加，合金表面张力降低。硫在表面上的浓度高于 内部。硫在 Ti-Al 合金中的吸附属于正吸附。
\end{abstract}

关键词：Ti-Al 合金; 热力学性质; 表面张力

作者简介: 刘许旸, 女, 1988 年生, 博士, 讲师, 重庆大学航空航天学院, 重庆 400044, 电话: 023-65111256, E-mail: liuxuyangcqu@ 163.com 